Article

\title{
DEA Performance Measurements in Cotton Production of Harran Plain, Turkey: A Single and Double Bootstrap Truncated Regression Approaches
}

\author{
Tamer Işgın ${ }^{1, *}$, Remziye Özel ${ }^{1}$, Abdulbaki Bilgiç ${ }^{2}{ }^{\circledR}$, Wojciech J. Florkowski ${ }^{3}{ }^{(1)}$ and \\ Mehmet Reşit Sevinç 4 (i) \\ 1 Department of Agricultural Economics, Faculty of Agriculture, Harran University, 63050 Şanlıurfa, Turkey; \\ rozel@harran.edu.tr \\ 2 Department of Agricultural Economics, Faculty of Agriculture, Atatürk University, 25240 Erzurum, Turkey; \\ abilgic@atauni.edu.tr \\ 3 Department of Agricultural \& Applied Economics, University of Georgia, Athens, GA 30602, USA; \\ wojciech@uga.edu \\ 4 Department of Bozova Vocational School, Harran University, 63850 Şanlıurfa, Turkey; rsevinc@harran.edu.tr \\ * Correspondence: tisgin@yahoo.com; Tel.: +90-414-3183718
}

Received: 9 February 2020; Accepted: 17 March 2020; Published: 3 April 2020

\begin{abstract}
A single and a double bootstrap of data envelopment analysis examines Harran Plain cotton farming in Turkey. The single bootstrap technique was employed to derive the bias-corrected efficiency values under both constant returns to scale (CRS) and versus variable returns to scale (VRS) technologies while discriminating between the two technologies using a smoothed bootstrap test statistic. Results indicated that the farms operated under VRS technology. Given that VRS technology prevailed across Harran Plain cotton farmers sampled, we then determined factors affecting the bias-corrected technical efficiencies using the double bootstrap technique. Another important finding in the single bootstrap analysis is that cotton farmers in the region have a U-shaped technical efficiency based on the input and output scale. Thus, small-scale farmers tend to use their resources more efficiently in cotton farming than that of both medium- and large-scale farmers. Interestingly, the medium-scale farmers with resource inefficiency are at the forefront of the other two types of farmers (i.e., small-scale and large-scale) on the Harran Plain in Turkey. The results also showed that most of the farm and farmer specific as well as economic factors play a significant role in explaining the technical efficiency values.
\end{abstract}

Keywords: cotton; data envelopment analysis; efficiency measurement; single and double bootstrap; Turkey

\section{Introduction}

Cotton has strategic importance in Turkish agriculture, industry, and trade. Turkey is one of the top cotton-producing countries and produced 2,450,000 MT in 2017 [1], while the textile industry represents one of the leading sectors in the Turkish economy and accounted for $16 \%$ of total export value in 2017. Exports of ready-to-wear cotton items were worth $\$ 17$ billion and textiles were valued at $\$ 8$ billion in 2017 [2].

Rapid economic development and a changing demographic structure in Turkey has led to a fast increase in domestic demand for textile products. Specifically, due to the speedy increase in the number of textile and clothing stores and shopping centers throughout the country, domestic textile sales have increased significantly in recent years. Turkey's growing young population, migration to urban areas, refugee influx from Syria and other countries, and the increase in tourism have contributed 
to a substantial increase in the domestic consumption of cotton products. In 2017/2018, domestic consumption was expected to reach 1.57 MMT (7.2 million bales), a fivefold increase in the annual cotton consumption since the 1980s [2,3]. Turkish total cotton imports reached 401,000 MTs in 2018, of which nearly $30 \%$ (118,000 MTs) were imported from the United States [2]. The growing domestic demand for cotton has turned the previously net exporting country into a net importer since 1992.

Southeastern Anatolia, known as the Fertile Crescent or Upper Mesopotamia, covers $20 \%$ of all irrigable land in Turkey. The Southeastern Anatolian Project (SAP) has been a massive $\$ 32$ billion public development project intended to improve farmer welfare in the region [2,4]. When all irrigation schemes under that project are completed, an additional 1.7 million ha will double the country's irrigated farmland. The Southeastern Anatolia (SEA) region will cement its prominent position as a cotton supplier.

The Harran Plain, one of the largest plains in the SEA region covers 225,109 ha, of which 140,000 ha are currently being irrigated [2]. Local farmers view cotton as the most profitable crop. The cotton area increased more than fivefold between 1995 and 2017, reaching 116,391 ha with a harvest of 546,917 MTs [1]. The Harran Plain alone accounts for about $22 \%$ of the country's cotton production. However, both yield and quality are low due to inefficiencies. The main reasons for the inefficiency is excessive or inadequate use of inputs such as fertilizer, improved seeds, irrigation, and extension services, which helps explain the less than expected productivity of the cotton sector, as well as the internal inefficiency in the use of available farm resources such as land, labor, and capital in the SEA region. For example, the use of excessive water has been cited as one of the main causes of soil salinity, which leads to reduced yields in cotton production in the region [4,5]. The Ministry of Agriculture and Forestry (MAF) has been providing technical and financial assistance to farmers to build modern drip irrigation systems and prevent ecological problems by avoiding water wastage. The MAF efforts have focused on moving from open canal irrigation systems to closed systems to reduce water loss during transportation [2]. While cotton yield in the country $(1683 \mathrm{~kg} / \mathrm{ha})$ ranks third after China $(1751 \mathrm{~kg} / \mathrm{ha})$ and Brazil (1686 kg/ha) in general, in some years the yield in Turkey has been more than the other two countries [6]. The increased use of improved technologies and/or the efficiency of farmer input use in cotton production on the Harran Plain offers potential to close the yield gap permanently. As stated in one of earlier studies [7], improvements in cotton productivity in the region may result from more efficient input use. In the near future, growth in the region's cotton production, especially in the plain, can result from more efficient use of land, capital, labor, and other inputs, especially irrigation. Unfortunately, there are other external factors hindering the rational use of inputs by cotton producers in the country. For example, most of the inputs used in cotton farming are import-based, preventing the use of the desired inputs at full capacity as a result of swings in exchange rates. For example, when the January and year-end December periods are taken as a reference, the exchange rates of the USD (\$) against the Turkish Lira (TL) in 2011, 2012, and 2013 were $19.63 \%,-3.25 \%$, and $16.32 \%$, respectively, exhibiting high volatility with non-stationary structure. Of course, fuel and fertilizer are among the most vulnerable inputs exposed to the exchange rate uncertainty. As such, at a time when the appreciated Turkish Lira lowers the production costs, it would be possible to increase the amount of energy inputs such as fuel, pesticides, and fertilizer, as well as overhead inputs such as labor and capital, including land, which appears to be quasi-fixed in cotton production.

Although cotton is the most frequently cultivated crop in the Harran plain, little is known concerning farmers' efficiency in the use of production inputs. In addition, all of the above-mentioned problems show that the input-oriented approach to solving problems in cotton production would be more rational and advantageous than alternative techniques. Additionally, as in other production sectors (industry and service sectors), the decision-making units (DMU) in the agricultural sector have more control over inputs than they have over outputs. An input-oriented approach was therefore used in our analysis of technical efficiency. Meanwhile, the research on the technical efficiency of cotton production and the determinants of the variability of efficiency levels among farmers with advanced analysis techniques is almost non-existent in the region or in the country. Therefore, this study attempts 
to analyze the technical efficiency of cotton production on the Harran Plain using an up-to-date data enveloping analysis, DEA, (including the application of the double bootstrap technique) and seeks to close the current knowledge gap by providing empirical evidence on resource utilization efficiency. In this context, the available double bootstrap DEA techniques developed by Simar and Wilson [8], hereafter SW, were applied to the data. SW have empirically shown that the traditional two-stage DEA method (TTS-DEA) involves severe limitations. First, the TTS-DEA method is incompatible with the underlying data generation process (DGP) to produce meaningful statistical properties (e.g., unbiasedness) to describe technical efficiency scores. Additionally, SW have shown the correlation of environmental factors with error term since input and output variables interact with environmental factors. Secondly, the DEA efficiency scores are serially correlated invalidating statistical inferences. To overcome the constraints, SW used a double bootstrap procedure with consistent inferences to explain and predict efficiency scores with valid standard errors and confidence intervals [9].

Another feature that distinguishes our study is that earlier studies have implemented a double bootstrap technique by choosing the technical efficiency of the farmers (e.g., constant returns to scale, CRS, versus variable returns to scale, VRS) based on verbal assumption without empirically testing, whereas this study empirically presents the existence of the farm technical efficiency by using a single bootstrap technique. After the return to scale parameters for the sampled farms, assuming either CRS or VRS are determined by conducting a statistical test based on a single bootstrap technique, a double bootstrap method was then applied to determine both the efficiency amount and non-discretionary factors playing roles in the efficiency of cotton production on the Harran Plain. Therefore, the current study is novel in this respect.

Included in the subsequent sections is the outline of methods used in the analysis and data description. Model comparison together with a specification test and discussion of the effects of variables on the DEA efficiency scores are given in Section 3. The final part presents conclusions along with some policy implications.

\section{Materials and Methods}

\subsection{Survey Design and Variable Selection for the Empirical Specification}

First, 51 villages inhabited by 1029 cotton farmers were purposely selected, thought to be representative of the study area. Next, a total of 126 cotton farmers were selected using a stratified random sampling design introduced by Yamane [10] with an allowable percentage error margin of $5 \%$. To assure the representativeness of the cotton farmer population, the selected farmers were divided into four size segments leading to a stratified distribution yielding 49, 49, 21, and 7 cotton farmers in each stratum. Farmer participation was voluntary. Farmers were supplied with diaries at the beginning of the 2012 production season. For the production season of 2012, we made a comparison between the variations in cotton yields obtained from the participant and non-participant farmers and no significant difference existed, indicating the Hawthorne effect was not present in our data set. In addition, we ascertain that our data set would not run into the problem of self-selection bias reasoning that our participatory farmers were randomly selected and even if the effects of both the self-selection bias and the Hawthorn are possible these effects would be offset thanks to the bootstrap technique used in this analysis. Meanwhile, in a standard DEA context, homogeneity in DMU's refers to the condition where all DMUs under investigation are subject to similar conditions in terms of the topography, climate, and commonly applied farming techniques. When we apply this perspective, the homogeneity requirement in DMU's in our data set is attained because all our farmers operate in the same region (the Harran Plains), face the same climatic conditions, and, therefore, apply similar farming techniques. Additionally, our output and input sets are constructed by taking representative (identical) measures into consideration. For example, while the farmers had a choice of using different fertilizer types, we converted those usages into the net nitrogen and phosphorous amounts. Similarly, in the calculation of family and hired labor, we converted the total number of hours and used the net 
man-hour equivalent instead. Thus, we met the homogeneity requirement across all DMUs for every input used and output produced by the cotton sector of the Harran Plain region.

The recording of the information was controlled by 10-20 visits to farmers throughout the season depending on the village location. Such an approach built a trusted relationship between the survey workers and the farmers, which better motivated farmers, minimizing the risk of recording false entries. Farmers received payments for recording financial and production information after harvest. Each farmer was also interviewed on matters related to (1) production characteristics, including measures such as size of the operation, ownership type, yields, and land characteristics; and (2) farmer characteristics such as gender, age, and education (Table 1). After deleting an outlier value in one of our inputs in DEA, the remaining 125 farms formed our working sample. Table 1 lists definitions of variables used in the empirical analyses including units of measurement. Five variables (e.g., seed (SEED), the amounts of nitrogen and phosphorus (FRTLZR), family and hired labor (LABOR), herbicide and insecticide value (PESTICIDE), and value of working capital (OTHRCAP) capture the inputs used in cotton production per decare (YIELD).

Table 1. Descriptive statistics for variables used in econometric analysis.

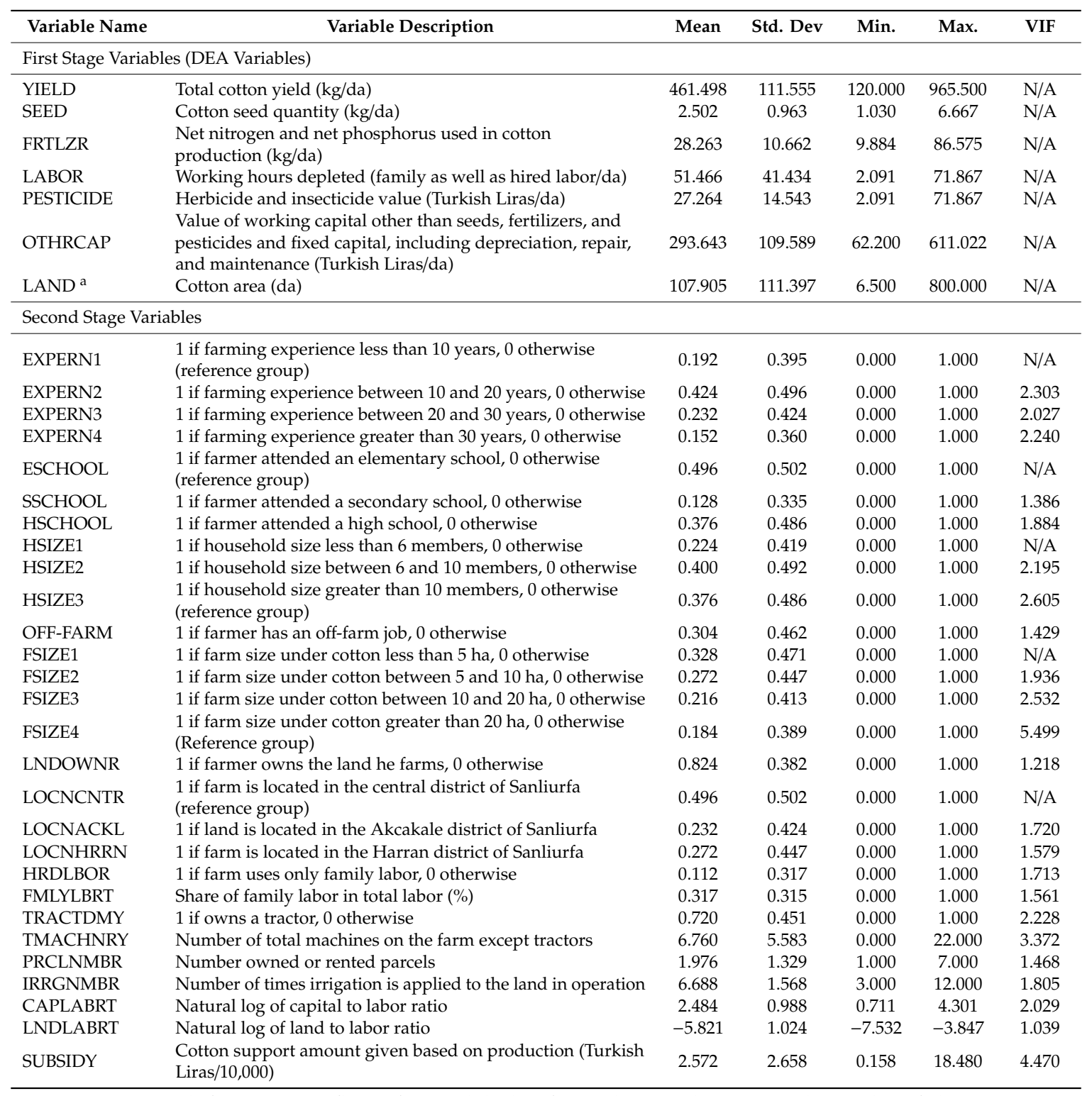

Note: VIF stands for variance inflation factor while da refers to decare or hectare/10. The number of observations $(\mathrm{N})$ is $125 .{ }^{\text {a }}$ LAND variable was not used in the DEA analysis. 
Farm and farmer characteristics used as explanatory variables affecting DEA efficiency scores include mutually exclusive multiple dummy variables representing farmer experience (Table 1), household size, education level, location, and farm size along with single dummy variables indicating off-farm work and land ownership. Other performance-related determinants that are discrete in nature include farmer age in years, the number of parcels owned or rented, and the irrigation frequency (the time irrigation recurs on the field). The only performance-related determinant measured in continuous fashion is the percentage share of family labor input in the total labor force, ranging from zero to one.

Location dummies indicate the municipal division of the Sanliurfa province and are used to identify the impact of location on the farm performance. It is hypothesized that farmers located in the central district are more efficient than those located in the Harran and Akcakale districts because farmers in the central district may have easier access to information. To avoid the dummy identification problem, one of the location dummies is used as a reference variable. Similarly, land ownership could have an ambiguous impact on efficiency. For example, land ownership could create an incentive to use soil-improving techniques in favor of efficiency, while tenancy might encourage the tenant farmer to use inputs more efficiently. Additionally, the impact of the share of family labor has an ambiguous effect (positive or negative): a larger share of hired labor may imply a more specialized, and thus more productive labor, but it might also be a source of moral hazard [11]. Farmer age could be expected to have a positive impact on efficiency as older farmers are more experienced, but some authors discuss reasons for the opposite relationship [12], perhaps due to physical deficiencies as the farmer gets older (e.g., age impairment non-linearity). Similarly, higher efficiency scores are expected for farms where full-time experienced farmers are more educated, household size is smaller, farmer operates on the land parcels close to each other, and irrigates the land. In small-scale families, there may be an inter-individual division of labor in which each member specializes in his/her task, and this attitude can be seen as a factor that increases technical efficiency. On the other hand, technical efficiency in scattered parcels can, of course, be disadvantageous compared to peers in parcels that are close to each other.

\subsection{The Modeling Approach}

The DEA production frontier is constructed using linear programming techniques, which render a piece-wise linear frontier that envelops the observed input and output data. Technologies produced in this way possess the standard properties of convexity and strong disposability [13]. The DEA technique measures relative efficiencies of a collection of farms in transforming inputs into outputs. Its origins date back to Charnes et al. [14], who introduced the CCR model based on the works of Farrell [15] and others. Later, Banker et al. [16] introduced the BCC model and accounted for variable returns to scale by adding a convexity constraint. The original DEA specification has led to the multi-stage model development to cope with slacks and to meet criteria identifying the nearest efficient points [17] and making the model invariant to units of measurement.

An input-oriented DEA model is given below for $n$ decision-making units (farms), each producing $Y$ outputs by using $m$ different inputs. In this formulation $X_{i}$ is the $i$ th farm's $(m x 1)$ input vector. For the whole sample, $Y$ represents the $(1 \times n)$ cotton yield vector and $X$ denotes the $(m x n)$ input per decare matrix. Focusing on the unit area limits variability by minimizing the effects on input and output values. Under the assumption of constant returns to scale (CRS), the efficiency score is the set of solutions to the following linear programming problem:

$$
\begin{gathered}
\min \hat{\theta}_{i} \\
\hat{\theta}_{i}, \lambda \\
\text { subject to }-y_{i}+Y \lambda \geq 0 \\
\hat{\theta}_{i}, x_{i}-X \lambda \geq 0 \\
\lambda \geq 0
\end{gathered}
$$


where $\hat{\theta}$ is the technical efficiency score for the $i$ th farm; $\lambda$ is an $N x 1$ vector of constants, where $N$ is the number of farms in the sample; $y_{i}$ shows the $i$ th farm output per decare, while $x_{i}$ denotes a vector of inputs per decare used in the production of $y_{i}$ by the $i$ th farm; $Y_{\lambda}$ and $X_{\lambda}$ denote a projected point due to radial contraction of the input vector $x_{i}$. The objective of the above linear programming is to find the minimum $\hat{\theta}$ so that the input vector $x_{i}$ reduces to $X_{\lambda}$, while holding the output level $y_{i}$ constant. In this context, the value of $\hat{\theta}$ will range between zero and one, with a score of near-zero implying inefficiency, while a score of one implying a point on the frontier where the farm in the region is technically efficient. For a specification under variable returns to scale (VRS), the additional convexity constraint $\overline{1} \lambda=1$ is added to the above linear programming, where $\overline{1}$ is a vector of ones [16]. The constraint guarantees that an inefficient farm in the region is only benchmarked against units of a similar size. The scale efficiency (SE) of an $i$ th farm is obtained by dividing the technical efficiency scores under CRS to the technical efficiency scores under VRS and is at a $(0,1)$ interval. The approach allows the comparison of the technical efficiency under the CRS and VRS technologies by using a smoothed single bootstrap technique [18]. The bias-corrected technical efficiency values under both technologies were then derived.

When the SE is 1, the farm has an efficient economy of scale, otherwise, inputs used in production are not efficient in scale [19]. To determine under what scale these technical efficiencies are derived, the test is applied whether the scale efficiency is 1 (CRS) or against the alternative hypothesis that the $S E<1$ (VRS). The test statistic is:

$$
S=\left(\sum_{i=1}^{N} \hat{\theta}_{i}^{C R S}\right) /\left(\sum_{i=1}^{N} \hat{\theta}_{i}^{V R S}\right)
$$

and the $H_{0}$ is rejected if $S$ is significantly smaller than one. As such, a critical threshold value $\left(C_{\alpha}\right)$ for statistic $S$ is searched and if this critical value $C_{\alpha}$ is smaller than $S$, the $H_{0}$ hypothesis is rejected. Unfortunately, the true distribution of $S$ under $H_{0}$ is unknown (the hypothesis of CRS) so $C_{\alpha}$ cannot be directly calculated, but Simar and Wilson $[8,18]$ showed that one can bootstrap the distribution of $S$ under $H_{0}$ in their FEAR $\mathrm{R}$ package (FEAR $\mathrm{R}$ package, obtains bootstrapped CRS and VRS, respectively, as follows: $\mathrm{Bc}<-$ boot.sw98 $(\mathrm{x}, \mathrm{y}, \mathrm{NREP}=$ nrep, RTS $=3)$ and $\mathrm{Bv}<-$ boot.sw98 $(\mathrm{x}, \mathrm{y}, \mathrm{NREP}=$ nrep, RTS $=1, \mathrm{XREF}=\mathrm{x}, \mathrm{YREF}=\mathrm{y}, \mathrm{DREF}=1 / \mathrm{e})$, where RTS $=3$ and RTS $=1$ for CRS and VRS, respectively; nrep is the number of bootstrap replications (e.g., here, 10,000), and DREF $=1 / \mathrm{e}$, where $1 / \mathrm{e}$ is the efficiency score under the CRS technology. The estimated value of $S$ in R package can be called for $S<$ $-\operatorname{colSums}(1 / \mathrm{Bc} \$$ boot $) / \operatorname{colSums}(1 / \mathrm{Bv} \$$ boot $)$, while in benchmark package in $\mathrm{R}$, critValue $(S, 0.05)$ reports the $C_{\alpha}$ value for the test).

The next step quantifies the technical efficiency scores by non-discretionary factors using a double bootstrap technique after empirically revealing the derived technical efficiency values. The quantification involves taking the inverse of the technical efficiency values in Equation (1) and defining it as $\hat{\delta}_{i}=\left(1 / \hat{\theta}_{i}\right)$. As a result, the variable dependent on the set of non-discretionary variables is transformed from the double boundary dimension to the single boundary dimension. In such a case, $\hat{\delta}_{i}$ is confined to the interval $\hat{\delta}_{i} \epsilon[1, \infty)$ and the left-limit truncation regression is used to determine factors associated with the reciprocal of the technical efficiency scores. The value of $\hat{\delta}_{i}$ equals one indicates an efficient farm, while the larger $\hat{\delta}_{i}$ value indicates an inefficient operation.

The relation between the dependent variable and non-discretionary variables can be shown as:

$$
\hat{\delta}_{i}=z_{i}^{\prime} \beta+\varepsilon_{i} \text {, subject to }: \hat{\delta}_{i} \geq 1
$$

where $z^{\prime}$ is an $(N x K)$ matrix of non-discretionary variables, $\beta$ is a vector of associated parameters to be estimated, and $\varepsilon_{i}$ is a continuous idd random error term. Given the necessity of $\hat{\delta}_{i} \geq 1-z_{i}^{\prime} \beta, \varepsilon_{i}$ is distributed normally with left truncation at $\left(1-z_{i}^{\prime} \beta\right)$ and standard deviation $\sigma_{\epsilon}$. Under this assumption, 
the parameters of the model in Equation (3) are obtained using the following left-truncated likelihood function:

$$
L=\prod_{i=1}^{N}\left(\frac{1}{\sigma_{\varepsilon}}\right) \varnothing\left(\frac{\hat{\delta}_{i}-z_{i}^{\prime} \beta}{\sigma_{\varepsilon}}\right)\left[1-\Phi\left(\frac{1-z_{i}^{\prime} \beta}{\sigma_{\varepsilon}}\right)\right]^{-1}
$$

where $\varnothing$ and $\Phi$ are the univariate probability density and cumulative distribution functions for the standard normal, respectively. Fortunately, as long as the data generating process (DGP) is defined, the double bootstrap technique can be used to empirically approximate the sampling distributions of $\beta$ and $\sigma_{\epsilon}$ and construct the confidence interval for proper inferences [20]. Detailed information about how the bootstrap works is included in the appendices provided at the end of this manuscript.

\section{Results and Discussion}

Table 2 shows computed efficiency scores under the assumptions of CRS and VRS. Using the original DEA technique, the uncorrected average efficiency scores are 71.20 and 83.50 (Table 2) for CRS and VRS, respectively.

Table 2. Descriptive statistics of technical efficiency scores.

\begin{tabular}{|c|c|c|c|c|c|c|}
\hline Variables & Mean & Std. Dev. & Min. & Max. & Lower $95 \%$ CI & Upper $95 \%$ CI \\
\hline \multicolumn{7}{|l|}{ CRS } \\
\hline Uncorrected TEx100 & 71.20 & 19.10 & 26.10 & 100 & $67.84^{b}$ & $74.57^{b}$ \\
\hline$\%$ of $\mathrm{TE}=1$ & 12.80 & & & & & \\
\hline$\%$ of $\mathrm{TE} \geq 0.90$ & 18.40 & & & & & \\
\hline$\%$ of $\mathrm{TE} \geq 0.50$ & 84.00 & & & & & \\
\hline Bias-corrected TEx100 & 64.11 & 16.20 & 23.70 & 90.50 & $59.20^{\mathrm{a}}$ & $70.10^{\mathrm{a}}$ \\
\hline & & & & & $61.25^{b}$ & $66.98^{b}$ \\
\hline$\%$ of $\mathrm{TE} \geq 0.90$ & 0.80 & & & & & \\
\hline$\%$ of $\mathrm{TE} \geq 0.50$ & 79.20 & & & & & \\
\hline \multicolumn{7}{|l|}{ VRS } \\
\hline Uncorrected TEx100 & 83.50 & 13.90 & 39.70 & 100 & $81.05^{b}$ & $85.95^{b}$ \\
\hline$\%$ of $\mathrm{TE}=1$ & 21.60 & & & & & \\
\hline$\%$ of $\mathrm{TE} \geq 0.90$ & 37.60 & & & & & \\
\hline$\%$ of $\mathrm{TE} \geq 0.50$ & 99.20 & & & & & \\
\hline Bias-corrected TEx100 & 76.75 & 11.60 & 36.50 & 93.80 & $70.70^{a}$ & $82.90^{\mathrm{a}}$ \\
\hline & & & & & $74.70^{\mathrm{b}}$ & $78.80^{\mathrm{b}}$ \\
\hline$\%$ of $\mathrm{TE} \geq 0.90$ & 7.20 & & & & & \\
\hline$\%$ of $\mathrm{TE} \geq 0.50$ & 99.20 & & & & & \\
\hline
\end{tabular}

${ }^{a}$ The mean value of confidence interval of the bootstrap. ${ }^{b}$ The constructed confidence level of the interval around the mean value.

The results indicate that an average cotton farmer that performs as efficiently as its benchmark can achieve the same level of output using $28.8 \%$ and $16.5 \%$ fewer inputs, on average, under CRS and VRS, respectively. The original DEA efficiency scores range from 26.10 to 100 for CRS and from 39.70 to 100 for VRS. The farms with the worst performance could save approximately $74 \%$ of their inputs by shifting to the efficiency frontier.

The production under VRS technology is more efficient than that of CRS technology (Figure 1). The efficiency scores obtained from the VRS technology for 109 out of 125 farms (87.3\%) are greater than the efficiency scores obtained from the CRS technology, providing sufficient evidence that there is room to improve cotton production efficiency by modifying input use. Only 16 of 125 farms and 32 of 125 farms for CRS and VRS technologies, respectively, were found to be fully efficient. Interestingly, the VRS technology yields twice as many fully efficient farms than the CRS technology. Additionally, VRS values performed above $40 \%$ when the efficiency value was below $40 \%$ in CRS (Figure 1). (The higher efficiency of the VRS technology relative to that of the CRS technology is 
shown in Figure 1). The percentage of cotton farmers who use inputs at a $90 \%$ efficiency or above is $18.40 \%$ (approximately 23 farms) and 37.6\% (approximately 47 farms) under CRS and VRS technologies, respectively, showing the potential for a $10 \%$ reduction in input use without a decrease in cotton yield.

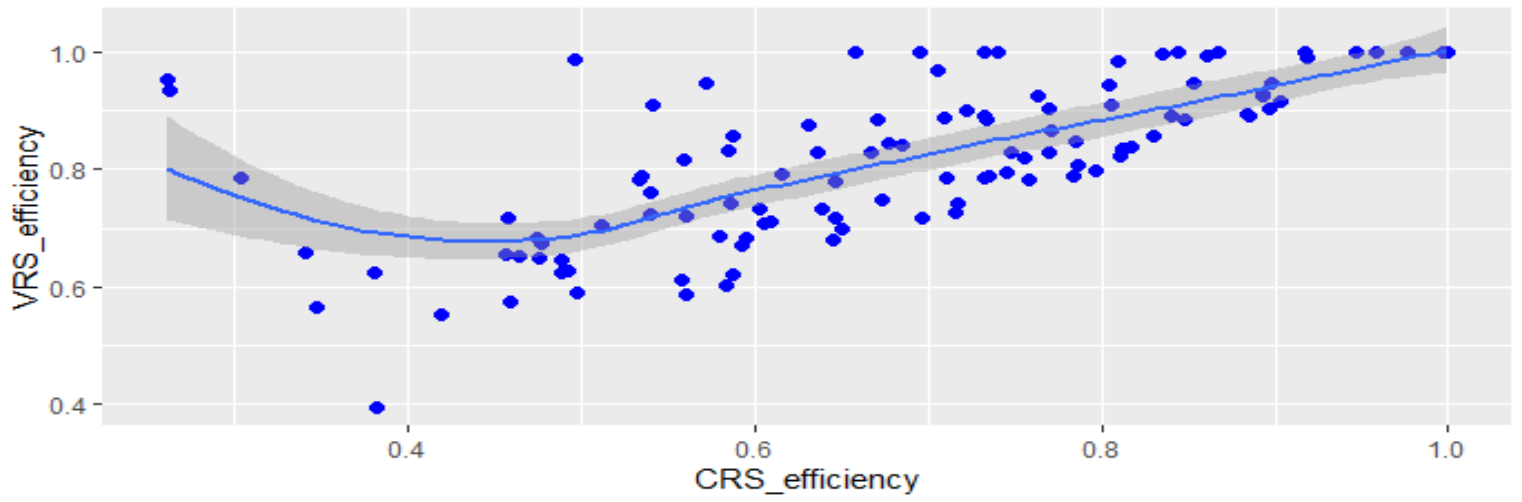

Figure 1. Technical efficiencies at CRS versus at VRS.

Table 2 compares the original DEA efficiency scores with those of the bias-corrected bootstrap efficiency estimators under CRS and VRS technologies. The bootstrap technique specified here, which is the focus of the discussion hereafter, includes the analysis of the first appendix (Appendix A) in the appendices. The signs of bias are negative for all input-oriented cotton production. All original efficiency scores under both technologies are greater than the bias-corrected results (Figure 2). At a performance below $60 \%$ in CRS, VRS is more likely to exceed this value in DMU. A similar situation can be extended to other technology levels.

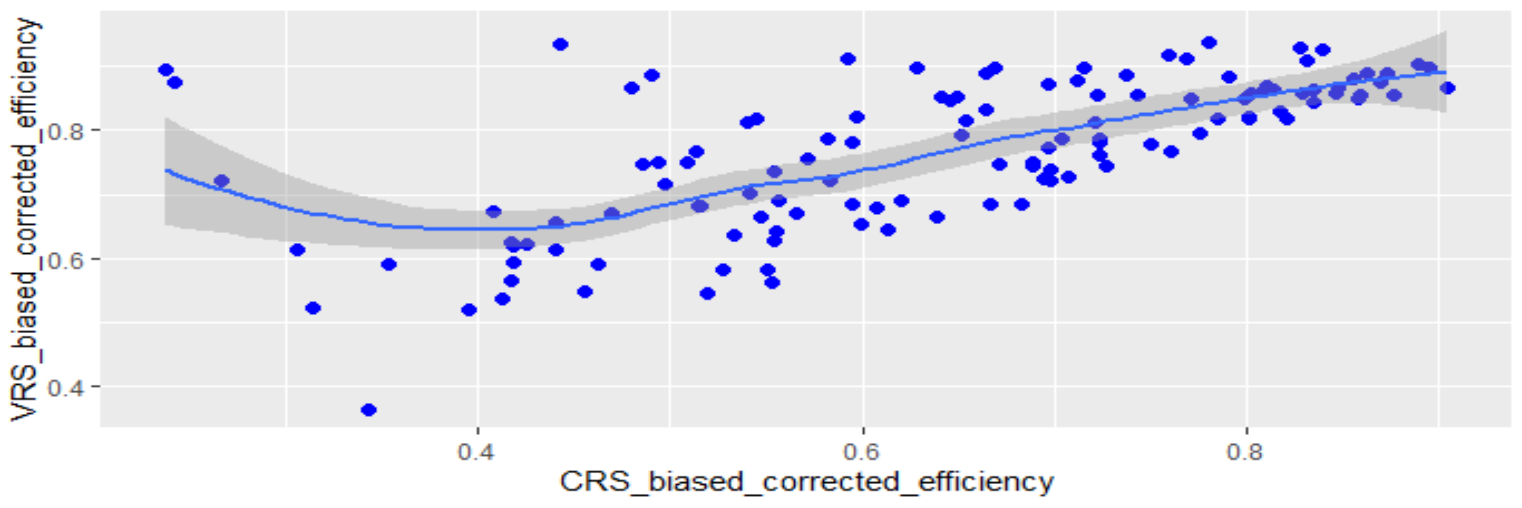

Figure 2. Biased corrected technical efficiencies at CRS versus at VRS.

The average efficiency scores for CRS and VRS are $64.11 \%$ and $76.75 \%$, respectively, indicating the opportunity for use from $35.89 \%$ to $23.25 \%$ for the same level of cotton yield (Table 2). For example, under the bias-corrected DEA, the efficiency of VRS technology outweighs the efficiency of CRS technology in yield of cotton production by about 12 points. Under the assumption of CRS technology with the bias-corrected DEA estimators, the share of farmers who use inputs efficiently at $50 \%$ or above and $90 \%$ or above is 79.20 and 0.80 percent points, respectively. The corresponding shares under VRS technology are $99.2 \%$ and $7.2 \%$, respectively. Under the VRS, the share of farmers who use $10 \%$ or fewer inputs inefficiently is $0.8 \%$ under the biased-corrected DEA, but it increases to $37.6 \%$ under the corresponding uncorrected DEA. Therefore, efficiency scores derived from the uncorrected (CRS or VRS) technologies tend to be upward biased. The uncorrected DEA bias was alleviated by the bootstrap technique (Figure 3). Under the CRS and VRS technologies, respectively, 20.8\% and $0.8 \%$ of the farms in the region have an efficiency score of less than $50 \%$. 


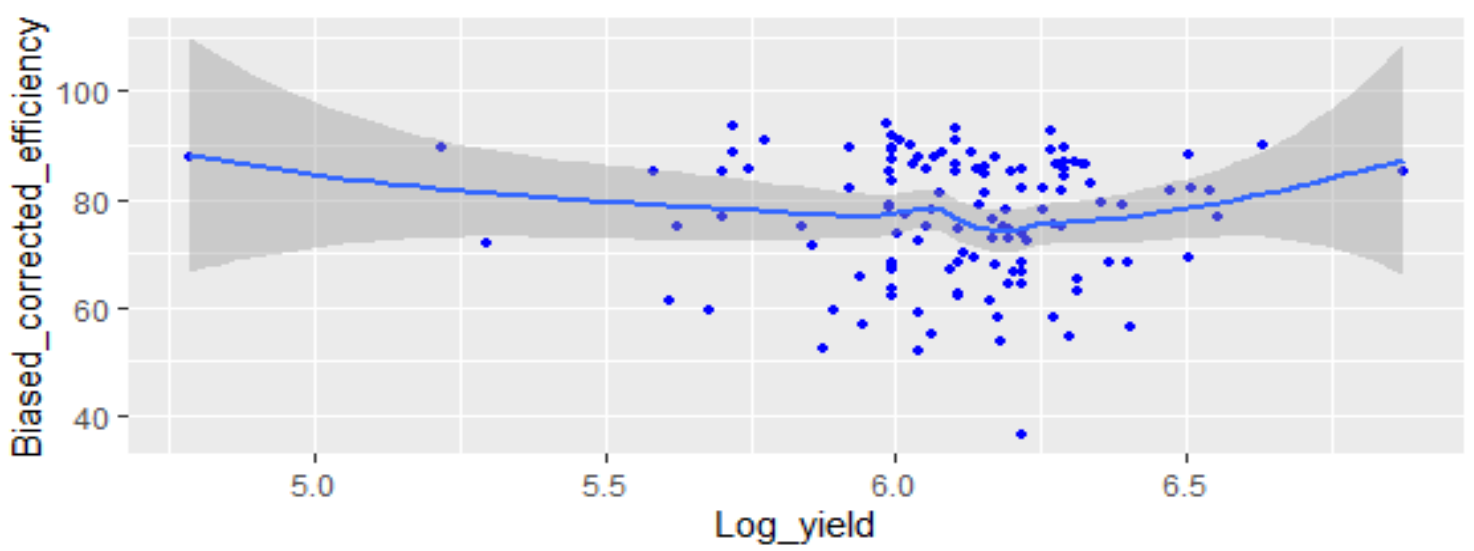

Figure 3. The relationship between VRS biased-corrected technical efficiency scores and natural logarithm of yield per decare.

The confidence interval for the mean value of the biased-corrected DEA efficiency scores can be calculated in two different ways. The confidence interval can be obtained by taking the averages of the confidence intervals calculated for the individual efficiency scores using the bootstrap estimators. The other, more robust method is the same as applied in calculating the confidence interval for the mean of the uncorrected DEA efficiency scores using the classical method. The choice of either method is unclear in the literature $[9,21-23]$. As can be seen in Table 2, the confidence intervals obtained from the average of the individual confidence intervals of the bootstrap technique are much larger than those obtained by the classical method. While the confidence intervals obtained from the mean of the individual confidence intervals of the bootstrap estimators indicate that the efficiency scores vary widely, the confidence intervals obtained by the classical method show that this variability is limited for both technologies. The uncorrected and bias-corrected DEA efficiency scores for both CRS and VRS technologies have similar confidence interval widths, while the unadjusted DEA scores for both technologies have a higher confidence interval. For example, the confidence interval obtained by the classical method for VRS technology implies that the farmers could reduce their inputs in cotton production by $14.05 \%-18.95 \%$ while maintaining the same level of yield.

To find out which operating technology is prevalent on the Harran Plain, one can test returns to scale parameters by using the DEA efficiency scores and bootstrapping procedure $[8,18,24]$. The null hypothesis of the prevalence of the CRS technology can be rejected if the estimated statistic is less than the critical value obtained by the bootstrapping estimators. The computed test statistic is $S=$ 0.8527 and the bootstrapping analysis computed the critical value of 0.9360 at $5 \%$ significance level, resulting in the rejection of CRS technology in favor of VRS technology. Such an outcome supported expectations based on the comparison between CRS and VRS technologies, making the VRS technology the dominant cotton production technology among the Harran Plain farmers.

The level of association between inputs, outputs, and biased-corrected efficiency levels was examined once the appropriate cotton production technology was identified. Table 3 classifies the inputs used in cotton production, using the logarithmic scale. The results indicate that farmers cluster in the third and fourth groups. In each input group, the bias-corrected technical efficiency variable showed a different structure and high variability in cotton production. Especially in the second, third, and fourth groups, the value of bias-corrected technical efficiency decreased sharply as the use of resources increased to achieve higher cotton output. However, in the fourth group, the average efficiency values recovered slightly more than the values in the other groups. Nevertheless, the value is still below the average value of the first group in the classification of all inputs used in cotton production. When farms expanded their inputs, up to $35 \%$ of input was wasted until the fourth group. Therefore, the diseconomies of scale in cotton production prevail, a cost disadvantage, leading to increase per unit-cost cotton production. 
Table 3. Relationships between inputs used in the production of cotton and bias-corrected efficiency of VRS technology.

\begin{tabular}{|c|c|c|c|c|c|c|}
\hline $\begin{array}{c}\text { Variable } \\
\text { Classifications }\end{array}$ & $\begin{array}{l}\text { Ln-Capital } \\
\text { Mean (Std. } \\
\text { Dev.) }\end{array}$ & $\begin{array}{l}\text { Ln-Labor } \\
\text { Mean (Std. } \\
\text { Dev.) }\end{array}$ & $\begin{array}{l}\text { Ln-Land } \\
\text { Mean (Std. } \\
\text { Dev.) }\end{array}$ & $\begin{array}{l}\text { Ln-Yield } \\
\text { Mean (Std. } \\
\text { Dev.) }\end{array}$ & $\begin{array}{c}\text { Bias-Corrected } \\
\text { Efficiency × } 100 \\
\text { Mean (Std. Dev.) }\end{array}$ & $\begin{array}{c}\text { Farm } \\
\text { Number }\end{array}$ \\
\hline \multicolumn{7}{|c|}{ Ln-Capital Classifications } \\
\hline$<8$ & $7.819(0.010)$ & $6.862(6.862)$ & $-0.327(0.147)$ & $6.240(0.053)$ & $76.424(14.205)$ & 2 \\
\hline $8 \leq$ Ln-Capital $<9$ & $8.584(0.345)$ & $6.935(0.763)$ & $0.610(0.318)$ & $5.993(0.299)$ & $83.437(6.320)$ & 9 \\
\hline$\geq 11$ & $11.510(0.402)$ & $8.633(0.865)$ & $3.112(0.462)$ & $6.059(0.254)$ & $74.257(12.476)$ & 32 \\
\hline \multicolumn{7}{|c|}{ Ln-Labor Classifications } \\
\hline$<6$ & $9.297(0.647)$ & $5.771(0.313)$ & $1.044(0.616)$ & $6.145(0.098)$ & $86.058(0.810)$ & 6 \\
\hline $6 \leq$ Ln-Labor $<7$ & $9.818(0.845)$ & $6.565(0.238)$ & $1.738(0.827)$ & $6.022(0.378)$ & $85.875(5.651)$ & 26 \\
\hline $7 \leq$ Ln-Labor $<8$ & $10.016(1.003)$ & $7.588(0.260)$ & $1.635(0.942)$ & $6.113(0.268)$ & $75.774(11.782)$ & 41 \\
\hline$<0$ & $7.819(0.010)$ & $6.862(0.091)$ & $-0.327(0.147)$ & $6.240(0.053)$ & $76.424(14.205)$ & 2 \\
\hline $0 \leq$ Ln-Land $<1$ & $8.940(0.476)$ & $7.079(0.695)$ & $0.648(0.227)$ & $6.183(0.267)$ & $79.398(11.057)$ & 16 \\
\hline $1 \leq$ Ln-Land $<2$ & $9.862(0.413)$ & $7.642(0.873)$ & $1.529(0.307)$ & $6.064(0.298)$ & $75.305(11.682)$ & 49 \\
\hline $2 \leq$ Ln-Land $<3$ & $10.763(0.469)$ & $7.842(1.183)$ & $2.475(0.281)$ & $6.161(0.239)$ & 77.380 (11.792) & 39 \\
\hline$\geq 3$ & $11.643(0.412)$ & $8.651(0.853)$ & $3.380(0.342)$ & $6.002(0.192)$ & 76.987 (11.913) & 19 \\
\hline
\end{tabular}

The relationship between the usage levels of aggregated inputs (e.g., capital, labor, and land), the cotton yield and corresponding biased-corrected efficiency scores are depicted in Figures 4-6. For example, when the cotton yield and efficiency performance of farmers are evaluated, an outward-looking U-shaped curve emerges (Figure 3). In cotton yield, it is observed that medium-sized farm enterprises are inefficient compared to small and large-scale farm enterprises. Agricultural enterprises with average cotton yield per decare have higher input losses compared to low and high yield enterprises in terms of yield production. These businesses can reach the same efficiency level by using less input on their cotton production. Business farms that plan high yields per decare generally use resource allocation efficiently, rewarding themselves with higher efficiency scores. On the other hand, when we look at the relationship between biased-corrected efficiency scores and capital input (Figure 4), it seems that the efficiency scores of the farmers who are poor in capital are higher than the farms with medium and high levels of capital. Therefore, the input losses of capital-intensive farms will be higher than the farms in other groups. This is most likely due to idle capital accumulation in farms (e.g., more than one tractor), and excess capital needs to be redirected towards the production of other products or combinations of production process.

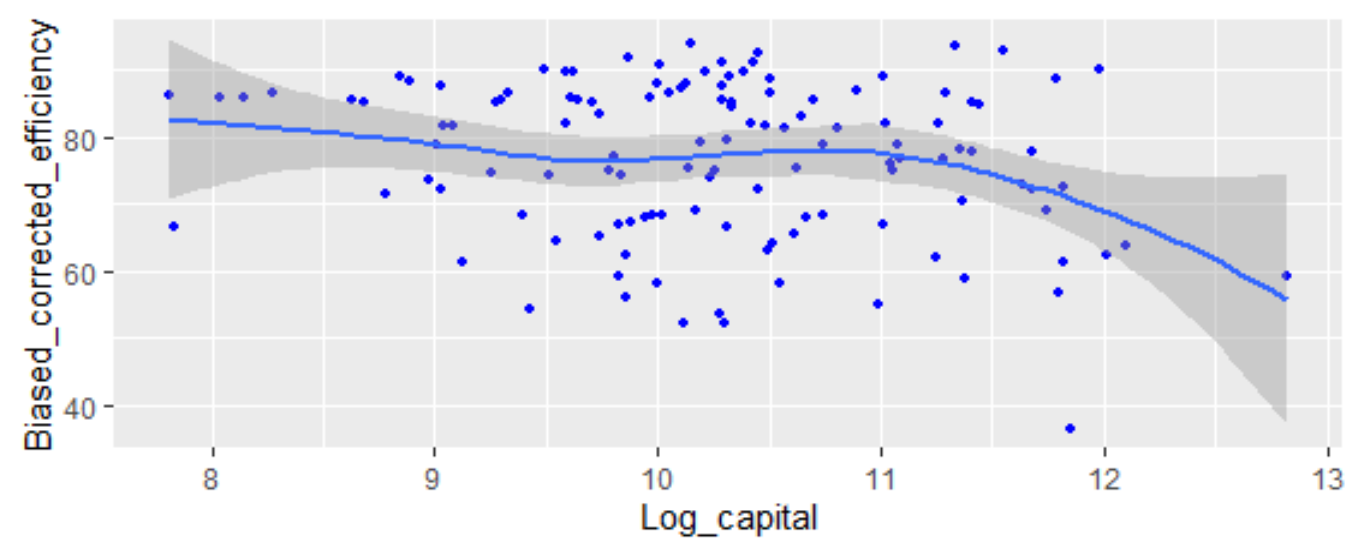

Figure 4. The relationship between VRS bias-corrected technical efficiency scores and natural logarithm of farm capital. 


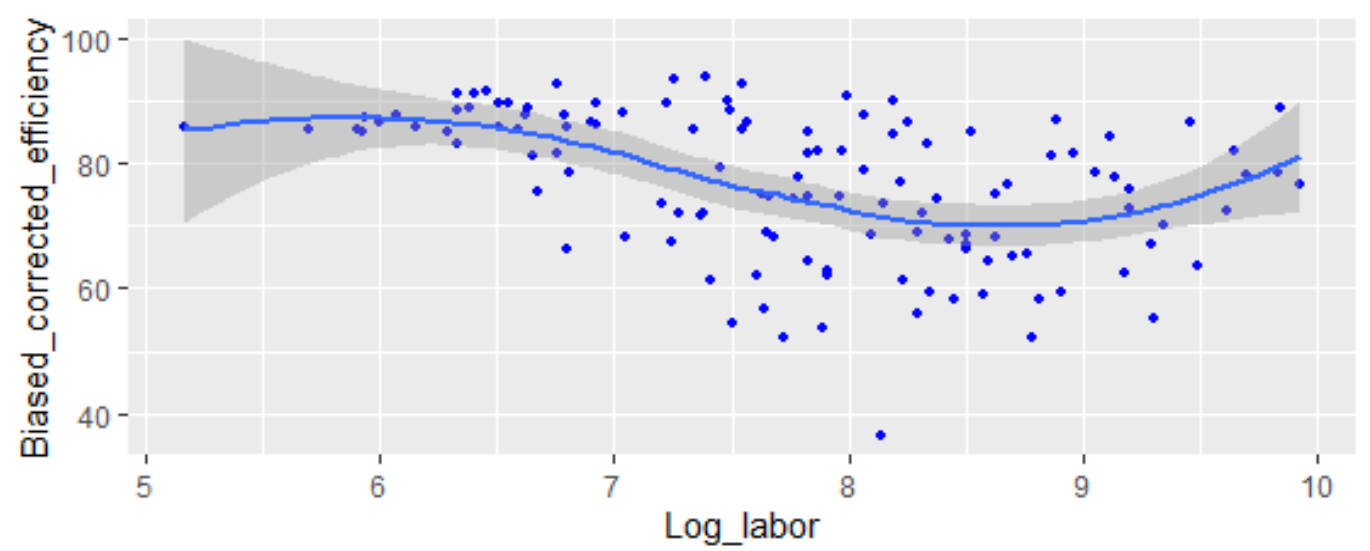

Figure 5. The relationship between VRS bias-corrected technical efficiency scores and natural logarithm of farm labor.

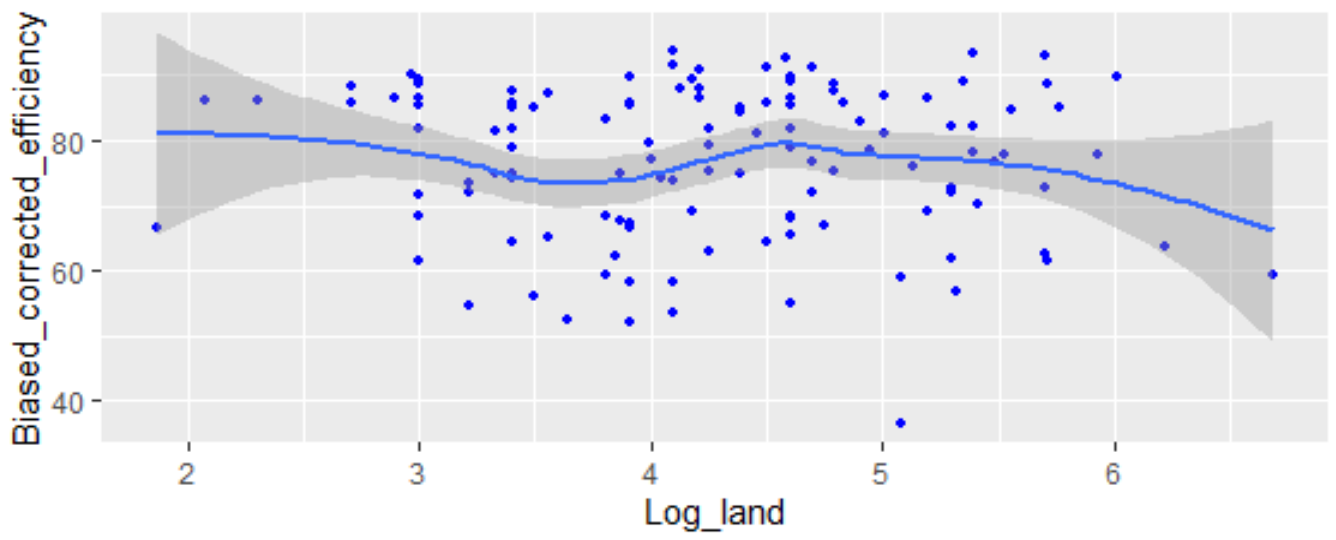

Figure 6. The relationship between VRS bias-corrected technical efficiency scores and natural logarithm of farm land (da).

There is a similar U-shaped relationship between efficiency values and farmers' labor input use levels (Table 3). Those who use medium-scale labor-intensive resources in cotton production will have higher input losses than the other two types of farm enterprises on the Harran Plain. Considering that such cotton farm enterprises are in sharecropper (tenant) types, it is possible for them to reach the cotton yield level of small and high-scale enterprises by making more savings in the amount of labor. The relationship between the land amount and efficiency scores is similar to the relationship between capital and activity. It seems the presence of distant fragmented land will decrease the efficiency in cotton production.

The level of relationship between the land amount and efficiency scores is similar to the level of the relationship between capital and activity. It seems that the amount of land will become more difficult as the cotton production plan becomes difficult, or perhaps the presence of distant fragmented land will decrease the efficiency in cotton production. Overall, the bias-corrected technical efficiency values in the region resemble a U-shaped curve, i.e., the most efficient cotton farms were the smallest and the largest. However, the results from the smallest cotton farms require attention because of the large farm number in the sample yet few of them in each input group (Table 3). Lerman [25] and Latruffe et al. [26] indicated low technical efficiency among the mid-scale farms. The region may develop remediation programs for farmers who waste resources in cotton production.

Table 4 shows the parameters of the bias-corrected efficiency values along with their confidence interval values derived from the double bootstrap technique for the truncated regression model (see Appendix B). The subsequent discussion is based on the bias-corrected technical efficiency scores and covers only statistically significant variables. Since the dependent variable is the reciprocal of 
bias-corrected technical efficiency in the double bootstrap analysis, the technical efficiency decreases with positively signed parameters and increases with negatively signed parameters.

Table 4. Estimates of non-discretionary variables from the double bootstrap analysis.

\begin{tabular}{|c|c|c|c|c|c|c|c|}
\hline \multirow[t]{2}{*}{ Variables } & \multirow{2}{*}{$\begin{array}{l}\text { Bias-Corrected } \\
\text { Estimates }\end{array}$} & \multicolumn{2}{|c|}{$\begin{array}{l}90 \% \text { Confidence } \\
\text { Interval }\end{array}$} & \multicolumn{2}{|c|}{$\begin{array}{l}\text { 95\% Confidence } \\
\text { Interval }\end{array}$} & \multicolumn{2}{|c|}{$\begin{array}{l}99 \% \text { Confidence } \\
\text { Interval }\end{array}$} \\
\hline & & Lower CI & Upper CI & Lower CI & Upper CI & Lower CI & Upper CI \\
\hline INTERCEPT & $-8.3126^{* * *}$ & -11.3140 & -6.7506 & -11.6417 & -6.2699 & -12.4395 & -5.1379 \\
\hline EXPERN2 & -0.1077 & -0.2451 & 0.0156 & -0.2673 & 0.0410 & -0.3196 & 0.0886 \\
\hline EXPERN3 & -0.0870 & -0.2309 & 0.0492 & -0.2593 & 0.0779 & -0.3048 & 0.1308 \\
\hline EXPERN4 & 0.0019 & -0.1574 & 0.1685 & -0.1837 & 0.1980 & -0.2580 & 0.2558 \\
\hline SSCHOOL & -0.0657 & -0.2064 & 0.0816 & -0.2363 & 0.1129 & -0.2821 & 0.1811 \\
\hline HCSCHOOL & 0.0083 & -0.1110 & 0.1300 & -0.1333 & 0.1553 & -0.1813 & 0.2076 \\
\hline HSIZE2 & $0.1992^{* * *}$ & 0.0772 & 0.3431 & 0.0459 & 0.3702 & -0.0138 & 0.4082 \\
\hline HSIZE3 & $0.2937^{* * *}$ & 0.1653 & 0.4603 & 0.1297 & 0.4850 & 0.0711 & 0.5237 \\
\hline OFF-FARM & -0.0709 & -0.1844 & 0.0391 & -0.2086 & 0.0619 & -0.2491 & 0.1028 \\
\hline FSIZE2 & -0.0575 & -0.1786 & 0.0601 & -0.2033 & 0.0851 & -0.2455 & 0.1359 \\
\hline FSIZE3 & $-0.1539 *$ & -0.3166 & -0.0135 & -0.3463 & 0.0114 & -0.4049 & 0.0759 \\
\hline FSIZE4 & -0.2068 & -0.4394 & 0.0162 & -0.4813 & 0.0656 & -0.5663 & 0.1647 \\
\hline LNDOWNR & $0.1459 * *$ & 0.0123 & 0.3076 & -0.0147 & 0.3277 & -0.0817 & 0.3906 \\
\hline LOCNACKL & -0.0339 & -0.1691 & 0.0960 & -0.1914 & 0.1234 & -0.2425 & 0.1760 \\
\hline LOCNHRRN & 0.0139 & -0.1031 & 0.1296 & -0.1249 & 0.1534 & -0.1670 & 0.2010 \\
\hline HRDLBOR & $0.1873 *$ & 0.0303 & 0.3879 & -0.0065 & 0.4209 & -0.0851 & 0.5002 \\
\hline FMLYLBRT & $0.2804^{* *}$ & 0.1025 & 0.5133 & 0.0640 & 0.5586 & -0.0278 & 0.6218 \\
\hline TRACTDMY & 0.0122 & -0.1252 & 0.1468 & -0.1482 & 0.1746 & -0.2040 & 0.2192 \\
\hline TMACHNRY & 0.0046 & -0.0088 & 0.0181 & -0.0115 & 0.0212 & -0.0170 & 0.0257 \\
\hline PRCLNMBR & $0.0753^{* * *}$ & 0.0458 & 0.1188 & 0.0386 & 0.1250 & 0.0253 & 0.1380 \\
\hline IRRGNMBR & -0.0259 & -0.0612 & 0.0084 & -0.0685 & 0.0156 & -0.0850 & 0.0301 \\
\hline CAPLABRT & $1.0188^{* * *}$ & 0.8338 & 1.3413 & 0.7790 & 1.3848 & 0.6580 & 1.4729 \\
\hline LNDLABRT & $-1.1403^{* * *}$ & -1.4835 & -0.9559 & -1.5246 & -0.9043 & -1.6105 & -0.7841 \\
\hline SUBSIDY & 0.0243 & -0.0028 & 0.0538 & -0.0085 & 0.0607 & -0.0184 & 0.0727 \\
\hline SIGMA & $0.2202^{* * *}$ & 0.2198 & 0.2805 & 0.2126 & 0.2860 & 0.1982 & 0.2968 \\
\hline
\end{tabular}

Note: ${ }^{*},{ }^{* *}{ }^{* * *}$ show statistically significance levels at $10 \%, 5 \%$, and $1 \%$, respectively.

The covariate that significantly and negatively impacts the bias-corrected efficiency scores is the household size. Thus, the bias-corrected technical efficiency scores under the assumed VRS technology increase as the household size increases. This finding is consistent with research reported elsewhere [27]. The increase in household size can pose a challenge, especially if children are present because the adults may not allocate time to cotton production when needed. This finding coincides with that reported by Coelli et al. [19].

Having an off-farm job negatively impacts farm technical efficiency. While this is a weak trend and the finding is not consistent with a previous study [12], it is in keeping with all findings reported earlier [19,22]. Farmers with non-agricultural income may have to concentrate resources on non-agricultural businesses which may lead to less efficiency on farms.

Cotton yield efficiency decreases gradually in the region as the size of agricultural farms increases compared to small-scale enterprises (less than $5 \mathrm{ha}$ ) and the results coincide with the findings of the international literature [7,26,28-32], while they contradict findings reported by Wadud and White [33], Latrufe et al. [9], and Balcombe et al. [22]. While cotton farmers in Akçakale are less efficient than farmers in the central district, farmers in the Harran district are more efficient than those in the central district, but the differences are statistically insignificant. It might be due to easier access to information and the proximity of the relevant private and public institutions to farmers in the central district.

Technical efficiency declines for farms dependent entirely on hired labor. Such farms are deprived of control over the business, while the work division might not have been fully rationalized among employees. In contrast with this finding, Latruffe et al. [26] and Olson and $\mathrm{Vu}$ [23] found that hired labor increased the technical efficiency of farms. Technical efficiency increases with the ratio of 
family to total labor. This finding supports the previous result which showed the positive effect of family workforce on efficiency scores. Although the results were found to be statistically insignificant, the more tractors, machinery, and equipment farmers own, the more efficient cotton production in the region becomes. The results support the notion that the tractor can maintain the largest share in tool and machinery capital, while in general, it might be a proxy variable for high-income or large-scale farm enterprises. Since the tractor can be simultaneously used in more than one production pattern, input usage time or harvest time may sometimes overlap in different fields or different crops. Therefore, overlapping time can, of course, pose a reduction in technical efficiency. Additionally, surprisingly the average technical efficiency of a cotton farm increases as the number of operated parcels, owned or rented, increases, as long as these parcels are close together, giving farmers the chance to manage their products simultaneously.

Technical efficiency increases with an increase in the ratio of capital to labor, while it decreases with an increase in the ratio of land to labor. Such findings correspond to earlier reports $[9,26]$ and indicate planned and rational distribution of resource use by some over-capital farms in cotton production process, whilst they are compatible with the effects of tractor and machine variables on efficiency on the Harran Plain. A confirmed negative relation between technical efficiency and land to labor ratio indicates that the amount of land per-hourly unit of labor decreases the technical efficiency of cotton farming, contradicting earlier results of Olson and $\mathrm{Vu}$ [23]. The efficiency values increase as the amount of support given to cotton by the government increases, although its impact was not statistically significant. Cash supports may be more effective when given during the production process.

\section{Conclusions}

The current inquiry's focus is twofold. First, the study investigated the relative performance measurements of farms using a random sample of 125 cotton farmers operating on the Harran Plain, Turkey, and applying the single bootstrap approach (Appendix A). Results revealed that the bias-corrected technical efficiency scores under the assumptions of CRS and VRS technologies averaged $71.20 \%$ and $83.50 \%$, respectively, implying that sampled cotton farmers wasted $28.8 \%-16.5 \%$, respectively, of inputs. Concerning the average efficiencies, poor input use has contributed to declining technical efficiency. Meanwhile, overuse of input ranging from around $17 \%$ to $29 \%$ poses a major threat to the environment on the Harran Plain, while it is also economically indispensable. The biased and bias-corrected technical efficiency values under the assumption of VRS were found higher than those computed under CRS technology. The finding has been further confirmed by a statistical test to generate its critical value using a bootstrap technique.

Another important result in the single bootstrap analysis is that the cotton farms are characterized by a U-shaped technical efficiency based on the input and yield scale. Thus, small- and large-scale farms use inputs more rationally than medium-size farms, wasting relatively less input to produce the same cotton output per decare. Additionally, medium-size farms need to balance capital, labor, and land against input applications. The timing and frequency of irrigation to reach the same cotton production per decare may be another input that requires attention and could prevent not only excessive water use but long-term consequences associated with salinity.

This paper also applied a double bootstrapped truncated regression (DBTRM) to quantify the relation between non-discretionary and bias-corrected technical efficiency (Appendix B). The analysis takes place in a unique loop shown in the model section. The analysis of the marginal effects indicates that farmers engaged in agricultural work are likely to be technically more efficient. Although non-agricultural work offers informal education opportunities broadening knowledge, teaching new skills, and enriching experience, which might improve the ability to manage input use, it has not been found, unfortunately, to transfer this accumulated knowledge to agriculture. The understanding that technical efficiency increases with household size could provide an opportunity for the family workforce to increase cotton production. The result that coincides with an increase in technical efficiency was the land area decrease, supporting the notion that the household labor endowment 
does match the operated land area. Further investigation of the issue is warranted because the age structure of all household members and gender composition of the farm was not considered. Since the expansion of land operated by a farm is possible only by renting or buying land from another farmer in the region, creating job opportunities outside agriculture is a broader challenge faced by provincial and national governments.

The increase in technical efficiency in households having a tractor, but the same effect of other machinery likely reflects the use of a tractor for multiple purposes, not limited to fieldwork. It appears that only if other equipment is owned by a farm will technical efficiency increase. Future studies may collect more detailed data on tractors and other equipment to establish a more accurate link to technical efficiency.

The decreasing technical efficiency on farms using only hired labor indicates that the landowner allocates a limited amount of time to manage the farm. Possibly, the offered remuneration provides little incentive or the quality of hired labor is low. If the reason for using only hired labor results from the landowner having a job outside agriculture, the phenomenon may open a chance for the development of professional farm managers, who could improve cotton production, especially given the prevailing waste of inputs. Consistent with these results, technical efficiency increases as the ratio of family to total workforce increases, indicating that through a planned division of labor, the family can achieve a desired production yield in the region.

Factors that have a consistently positive impact on efficiency measures include the ratio of capital to labor and increased land fragmentation. The latter effect on efficiency scores is consistent with the generally accepted idea that farmers operating a large number of parcels tend to be more efficient. Addressing land fragmentation through policy is difficult because the reasons behind land fragmentation are often rooted in culture; encouraging land consolidation through targeted grants may be a more viable approach.

One possible limitation of this study is the lack of knowledge of the seed types and the kind of technology that farmers use. For example, if a distinction between conventional and organic cotton production could have been made, meta frontier analysis would have provided more robust results than the bootstrapped DEA analysis. A future study can investigate the impacts of farm and farmer characteristics on technical efficiency using the stochastic frontier approach. In that case, technical efficiency measures take into account differences in the sources from which errors originate. That perspective can attempt to distinguish between errors arising from farmer discretion and errors arising from systematic factors.

Author Contributions: Conceptualization, T.I. and A.B.; methodology, T.I.; software, T.I., A.B. and W.J.F.; validation, T.I., A.B., W.J.F., R.Ö. and M.R.S.; formal analysis, T.I., A.B. and W.J.F.; investigation, T.I. and M.R.S.; resources, M.R.S. and R.Ö.; data curation, T.I., R.Ö., A.B. and W.J.F.; writing-original draft preparation, T.I., M.R.S., and R.Ö.; writing—review and editing, T.I. and M.R.S.; visualization, M.R.S. and R.Ö.; supervision, T.I. All authors have read and agreed to the published version of the manuscript.

Funding: This research was funded by the Scientific and Technological Research Council of Turkey (TUBITAK), grant number $110 \mathrm{~K} 374$.

Acknowledgments: We are highly grateful to the Scientific and Technological Research Council of Turkey (TUBITAK) for supporting our project numbered as 110K374. Without their valuable contributions, this research could never have been completed. The findings, interpretations, and conclusions expressed in this article are solely those of the authors and do not necessarily represent the view of TUBITAK.

Conflicts of Interest: The authors declare no conflict of interest.

\section{Appendix A. Simar and Wilson's Algorithm \# 1}

The application of the single bootstrapping procedure follows four steps:

(1) the calculation of the original technical efficiency values for all farms in the sample $(i=1, \ldots$, $N)$ using Equation (1) and denotes them as $\hat{\theta}_{i}$. Next, a random sample of the original sample size $N$ is drawn from this smooth estimate and is denoted $\hat{\theta}_{i}^{*}, i=1, \ldots, N$; 
(2) a new pseudo data is constructed for $x_{i}^{*}$ and $y_{i}^{*}$, where $x_{i}^{*}=\left(\hat{\theta}_{i} / \hat{\theta}_{i}^{*}\right) x_{i}$ and $y_{i}^{*}=y_{i}$ for $i=1, \ldots$, $N$, with $y_{i}$ and $x_{i}$ the original output and input vectors of the $i$ th farm, respectively;

(3) new DEA efficiency score is obtained for each farm in the region by taking the previous pseudo data as a reference for each CRS and VRS conditions;

(4) steps (1) to (3) are repeated $B$ times to yield a set of $B$ new DEA either efficiency scores $\hat{\theta}_{i}^{*}, C R S$ or efficiency scores $\hat{\theta}_{i}^{*}$ VRS. Here, $B$ is set as 10,000 in each CRS and VRS application.

\section{Appendix B. Simar and Wilson's Algorithm \# 2}

Following Simar and Wilson's [24] Algorithm 2, the procedure is as follows:

Step 1 obtains the DEA technical efficiency scores $\left(\hat{\theta}_{i}\right)$ under determined scale using Equation (1). Now, take the reciprocal of the technical efficiency score by letting $\hat{\delta}_{i}=\left(1 / \hat{\theta}_{i}\right)$ where $\hat{\delta}_{i}$ bounds from one to infinity for $i=1, \ldots, N$ and it becomes compatible with the left-truncation regression, mostly used in output-oriented approach;

Step 2 uses the method of maximum likelihood for the left-limit truncation regression to estimate $\hat{\beta}$ of $\beta$ and $\hat{\sigma}_{\epsilon}$ of $\sigma_{\epsilon}$ in the left-limit truncation regression of $\hat{\delta}_{i}$ on non-discretionary variable $Z$, where $\hat{\delta}_{i}>0$;

Step 3 implies a loop for each $i=1, \ldots, N$ following four steps (i)-(iv) $B_{1}$ times to obtain $N$ set of bootstrap estimates $\left\{\hat{\delta}_{i, b}^{*}\right\}_{b=1}^{B_{1}}$ :

(i) draw $\varepsilon_{i}$ from $N\left(0, \hat{\sigma}_{\varepsilon}\right)$ distribution with left-truncation at $\left(1-z_{i}^{\prime} \hat{\beta}\right)$;

(ii) Compute $\delta_{i}^{*}=z_{i}^{\prime} \hat{\beta}+\varepsilon_{i}$;

(iii) construct a pseudo data set $\left(x_{i}^{*}, y_{i}^{*}\right)$ where $x_{i}^{*}=\left(\hat{\delta}_{i} / \hat{\delta}_{i}^{*}\right) x_{i}$ and $\left(y_{i}^{*}, y_{i}\right)$. Note that we can also construct the pseudo $x_{i}^{*}$ from the original DEA efficiency scores as

$x_{i}^{*}=\left[\left(1 / \hat{\theta}_{i}\right) /\left(1 / \hat{\theta}_{i}^{*}\right)\right] x_{i}=\left(\hat{\theta}_{i}^{*} / \hat{\theta}_{i}\right) x_{i}$, where $\hat{\theta}_{i}^{*}=z_{i}^{\prime} \hat{\beta}+\varepsilon_{i} ;$

(iv) using the above pseudo data set and the DEA in Equation (1) under the determined scale calculate pseudo efficient estimates $\hat{\delta}_{i}^{*}=1 / \hat{\theta}_{i}^{*}$ for $i=1, \ldots, N$;

Step 4 computes bias-corrected estimates $\hat{\delta}_{i}$ where bias $=\hat{\delta}_{i}-\hat{\delta}_{i}^{*}$, where $\hat{\delta}_{i}^{*}=\left(\left(1 / B_{1}\right) \sum_{b=1}^{B_{1}} \hat{\delta}_{i, b}^{*}\right)-\hat{\delta}_{i}$;

Step 5 regresses $\hat{\delta}_{i}$ on $z_{i}^{\prime}$ to estimate $\hat{\hat{\beta}}$ and $\hat{\hat{\sigma}}_{\varepsilon}$ using the maximum likelihood for the left-truncation;

Step 6 is a loop over the next three steps (i)-(iii) $B_{2}$ times to generate a set of bootstrap estimates $\left\{\left(\hat{\hat{\beta}}^{*}, \hat{\sigma}_{\varepsilon}^{*}\right)_{b}\right\}_{b=1}^{B_{2}}$

(i) for each $i=1, \ldots, N$ draw $\varepsilon_{i}$ from $N\left(0, \hat{\hat{\sigma}}_{\varepsilon}\right)$ distribution with left-truncation at $\left(1-z_{i}^{\prime} \hat{\beta}\right)$;

(ii) compute $\delta_{i}^{* *}=z_{i}^{\prime} \hat{\hat{\beta}}+\varepsilon_{i}$;

(iii) use the maximum likelihood method to estimate the truncated regression of $\delta_{i}^{* *}$ on $z_{i}^{\prime}$ to yield estimates $\hat{\hat{\beta}}^{*}$ and $\hat{\hat{\sigma}}_{\varepsilon}^{*}$;

Step 7 uses the bootstrap estimates $\left(\hat{\beta}^{*}\right.$ and $\left.\hat{\sigma}_{\varepsilon}^{*}\right)$ from Step 6 and the estimates $\left(\hat{\hat{\beta}}\right.$ and $\left.\hat{\hat{\sigma}}_{\varepsilon}\right)$ generated in Step 5 to construct $(1-\alpha)$ confidence intervals for original $\beta$ and $\sigma_{\varepsilon}$. The $(1-\alpha)$ confidence interval of the $j$ th element of the vector $\beta$ as the $\operatorname{Pr}\left(-b_{/ 2} \leq \hat{\beta}_{j}^{*}-\hat{\beta}_{j} \leq-a / 2\right) \approx 1-\alpha$ such that the estimated confidence interval is $\left[\hat{\hat{\beta}}_{j}^{*}+a_{/ 2}^{*}, \hat{\hat{\beta}}_{j}+b_{/ 2}^{*}\right]$.

\section{References}

1. TUIK. Crop Production Statistics. Available online: http://www.turkstat.gov.tr/PreTablo.do?alt_id=1001 (accessed on 12 May 2018).

2. Sirtioglu, I. Turkey Cotton and Products. Available online: https://apps.fas.usda.gov/newgainapi/api/report/ downloadreportbyfilename?filename=Cotton\%20and\%20Products\%20Annual_Ankara_Turkey_3-23-2018. pdf (accessed on 12 May 2019).

3. Pinar, M.; Akyll, N.; Er, S.; Ertürk, Y.E. Cotton Production Status and Projection Report: 1997-1998, 2nd ed.; Agricultural Economics and Policy Development Institute (TEPGE): Ankara, Turkey, 1998. (In Turkish) 
4. Basal, H.; Sezener, V. Turkey Cotton Report. In Proceedings of the 11th Regional Meeting of the International Cotton Advisory Committee, Antalya, Turkey, 5-7 November 2012; pp. 5-7.

5. Cullu, M.A.; Aydemir, M.; Qadir, M.; Almaca, A.; Ozturkmen, A.R.; Bilgic, A.; Agca, N. Implication of groundwater fluctuation on the seasonal salt dynamic in the Harran Plain, south-eastern Turkey. Irrig. Drain. 2010, 59, 465-476. [CrossRef]

6. Agricultural Production Statistics by Country. Available online: https://www.indexmundi.com/agriculture/ (accessed on 4 August 2019).

7. Binici, T.; Demircan, V.; Zulauf, C.R. Assessing production efficiency of dairy farms in Burdur province, Turkey. J. Agric. Rural Dev. Trop. Subtrop. 2006, 107, 1-10.

8. Simar, L.; Wilson, P.W. Statistical inference in nonparametric frontier models: The State of the Art. J. Prod. Anal. 2000, 13, 49-78. [CrossRef]

9. Latruffe, L.; Balcombe, K.; Davidova, S.; Zawalinska, K. Technical and scale efficiency of crop and livestock farms in Poland: Does specialization matter? Agric. Econ. 2005, 32, 281-296. [CrossRef]

10. Yamane, T. Statistics An Introductory Analysis, 2nd ed.; Harper and Row: New York, NY, USA, 1967.

11. Bojnec, Š.; Latruffe, L. Determinants of technical efficiency of Slovenian farms. Post Commun. Econ. 2009, 21, 117-124. [CrossRef]

12. Larsén, K. Effects of machinery-sharing arrangements on farm efficiency: Evidence from Sweden. Agric. Econ. 2010, 41, 497-506. [CrossRef]

13. Färe, R.; Grosskopf, S.; Norris, M.; Zhang, Z. Productivity Growth, Technical Progress, and Efficiency Change in Industrialized Countries. Am. Econ. Rev. 1994, 84, 66-83.

14. Charnes, A.; Cooper, W.W.; Rhodes, E. Measuring the efficiency of decision making units. Eur. J. Oper. Res. 1978, 2, 429-444. [CrossRef]

15. Farrell, M.J. The Measurement of Productive Efficiency. J. Royal Stat. Soc. Ser. A 1957, 120, 253-281. [CrossRef]

16. Banker, R.D.; Charnes, A.; Cooper, W.W. Some Models for Estimating Technical and Scale Inefficiencies in Data Envelopment Analysis. Manag. Sci. 1984, 30, 1078-1092. [CrossRef]

17. Koopmans, T. Activity Analysis of Production and Allocation, 1st ed.; John Wiley \& Sons: New York, NY, USA, 1951.

18. Simar, L.; Wilson, P.W. Sensitivity Analysis of Efficiency Scores: How to Bootstrap in Nonparametric Frontier Models. Manag. Sci. 1998, 44, 49-61. [CrossRef]

19. Coelli, T.; Rahman, S.; Thirtle, C. Technical, allocative, cost and scale efficiencies in Bangladesh rice cultivation: A non-parametric approach. J. Agric. Econ. 2002, 53, 607-626. [CrossRef]

20. Monchuk, D.C.; Chen, Z.; Bonaparte, Y. Explaining production inefficiency in China's agriculture using data envelopment analysis and semi-parametric bootstrapping. China Econ. Rev. 2010, 21, 346-354. [CrossRef]

21. Brümmer, B. Estimating confidence intervals for technical efficiency: The case of private farms in Slovenia. Eur. Rev. Agric. Econ. 2001, 28, 285-306. [CrossRef]

22. Balcombe, K.; Fraser, I.; Latruffe, L.; Rahman, M.; Smith, L. An application of the DEA double bootstrap to examine sources of efficiency in Bangladesh rice farming. Appl. Econ. 2008, 40, 1919-1925. [CrossRef]

23. Olson, K.; Vu, L. Economic efficiency in farm households: Trends, explanatory factors, and estimation methods. Agric. Econ. 2009, 40, 587-599. [CrossRef]

24. Simar, L.; Wilson, P.W. Estimation and inference in two-stage, semi-parametric models of production processes. J. Econ. 2007, 136, 31-64. [CrossRef]

25. Lerman, Z. Productivity and Efficiency of Individual farms in Poland: A Case for Land Consolidation. Available online: https://ageconsearch.umn.edu/record/19835 (accessed on 8 February 2020).

26. Latruffe, L.; Davidova, S.; Balcombe, K. Application of a double bootstrap to investigation of determinants of technical efficiency of farms in Central Europe. J. Prod. Anal. 2008, 29, 183-191. [CrossRef]

27. Aravindakshan, S.; Rossi, F.; Amjath-Babu, T.S.; Veettil, P.C. Application of a bias-corrected meta-frontier approach and an endogenous switching regression to analyze the technical efficiency of conservation tillage for wheat in South Asia. J. Prod. Anal. 2018, 49, 153-171. [CrossRef]

28. Berry, R.A.; Cline, W.R. Agrarian Structure and Productivity in Developing Countries: A Study Prepared for the International Labour Office Within the Framework of the World Employment Programme; John Hopkins University Press: Baltimore, MD, USA, 1979; ISBN 978-0-8018-2190-5.

29. Ramalho, E.A.; Ramalho, J.J.S.; Henriques, P.D. Fractional regression models for second stage DEA efficiency analyses. J. Prod. Anal. 2010, 34, 239-255. [CrossRef] 
30. Grabowski, R.; Kraft, S.; Pasurka, C.; Aly, H.Y. A ray-homothetic production frontier and efficiency: Grain farms in Southern Illinois. Eur. Rev. Agric. Econ. 1990, 17, 435-448. [CrossRef]

31. Barrett, C.B. On price risk and the inverse farm size-productivity relationship. J. Dev. Econ. 1996, 51, $193-215$. [CrossRef]

32. Helfand, S.M.; Levine, E.S. Farm size and the determinants of productive efficiency in the Brazilian Center-West. Agric. Econ. 2004, 31, 241-249. [CrossRef]

33. Wadud, A.; White, B. Farm household efficiency in Bangladesh: A comparison of stochastic frontier and DEA methods. Appl. Econ. 2000, 32, 1665-1673. [CrossRef] 